\title{
An Air Quality Management System for Policy Support in Cyprus
}

\author{
Nicolas Moussiopoulos, ${ }^{1}$ Ioannis Douros, ${ }^{1}$ George Tsegas, ${ }^{1}$ \\ Savvas Kleanthous, ${ }^{2}$ and Eleftherios Chourdakis ${ }^{1}$ \\ ${ }^{1}$ Laboratory of Heat Transfer and Environmental Engineering, Aristotle University, University Campus, P.O. Box 483, \\ 54124 Thessaloniki, Greece \\ ${ }^{2}$ Department of Labour Inspection, Ministry of Labour and Social Insurance, Apelli 12, 1480 Nicosia, Cyprus, Greece
}

Correspondence should be addressed to Ioannis Douros, jdouros@aix.meng.auth.gr

Received 13 February 2012; Accepted 22 March 2012

Academic Editor: Tareq Hussein

Copyright (C) 2012 Nicolas Moussiopoulos et al. This is an open access article distributed under the Creative Commons Attribution License, which permits unrestricted use, distribution, and reproduction in any medium, provided the original work is properly cited.

The recent air quality directive (2008/50/EC) encourages the introduction of modelling as a necessary tool for air quality assessment and management. Towards this aim, an air quality management system (AQMS) has been developed and installed in the Department of Labour Inspection (DLI) of the Republic of Cyprus. The AQMS comprises of two operational modules, providing hourly nowcasting and daily forecasting of the air quality status, implemented as an integrated model system that performs nested grid meteorological and photochemical simulations. A third operational module provides the capability of an interactive configuration of custom emission scenarios and corresponding model runs covering user-defined domains of interest. Statistical indicators are calculated at the end of each day for the measurement locations of DLI's air quality monitoring network. Besides, the system provides an advanced user interface, which is realised as a web-based application providing access to model results from any computer with an internet connection and a web browser.

\section{Introduction}

The new air quality directive (2008/50/EC) introduces additional requirements for air quality assessment and management. As a result, along with air quality measurements, modelling tools should also be used by authorities and policy makers in order to assess pollutant concentrations in ambient air. It also requires that up-to-date information on concentrations of all regulated pollutants in ambient air should be readily available to the public.

Towards this aim, an operational web-based system for air quality management developed by the Laboratory of Heat Transfer and Environmental Engineering (LHTEE) has been installed in the Department of Labour Inspection of the Ministry of Labour and Social Insurance in the Republic of Cyprus. The system offers a range of features for nowcasting, forecasting, and performing scenario calculation for air quality in Cyprus. Besides, a number of statistical indices [1] and validation maps are calculated at the end of each day at various points coinciding with the locations of DLI's air quality monitoring stations [2] in order to assess the system's accuracy.

The main goals of the system lie in providing useful upto-date information to the public on pollutant concentrations in ambient air, as well as supporting local authorities and decision makers in air quality assessment and management.

\section{Methodology}

The core of the system handles the compilation of an emissions inventory that includes data from all major activity sectors and functions on the basis of a continuous update of the emissions database. This part of the software dealing with emissions provides functionality for setting up emission scenarios based both on the application of measures as well as targeted modifications. Emission data are prepared as an emissions grid that is subsequently fed into the air quality modelling system [3]. 
TABLE 1: Description of MEMO and MARS-aero nested grids.

\begin{tabular}{|c|c|c|c|c|c|}
\hline & Depth of nesting & Number of nested grids & Grid size & Grid resolution & Type of nesting \\
\hline Coarse & \multirow{2}{*}{2} & 1 & $60 \times 60$ & $25 \mathrm{~km}^{2}$ & \multirow{2}{*}{ 1-way } \\
\hline Fine & & 5 & $50 \times 50$ & $1 \mathrm{~km}^{2}$ & \\
\hline
\end{tabular}

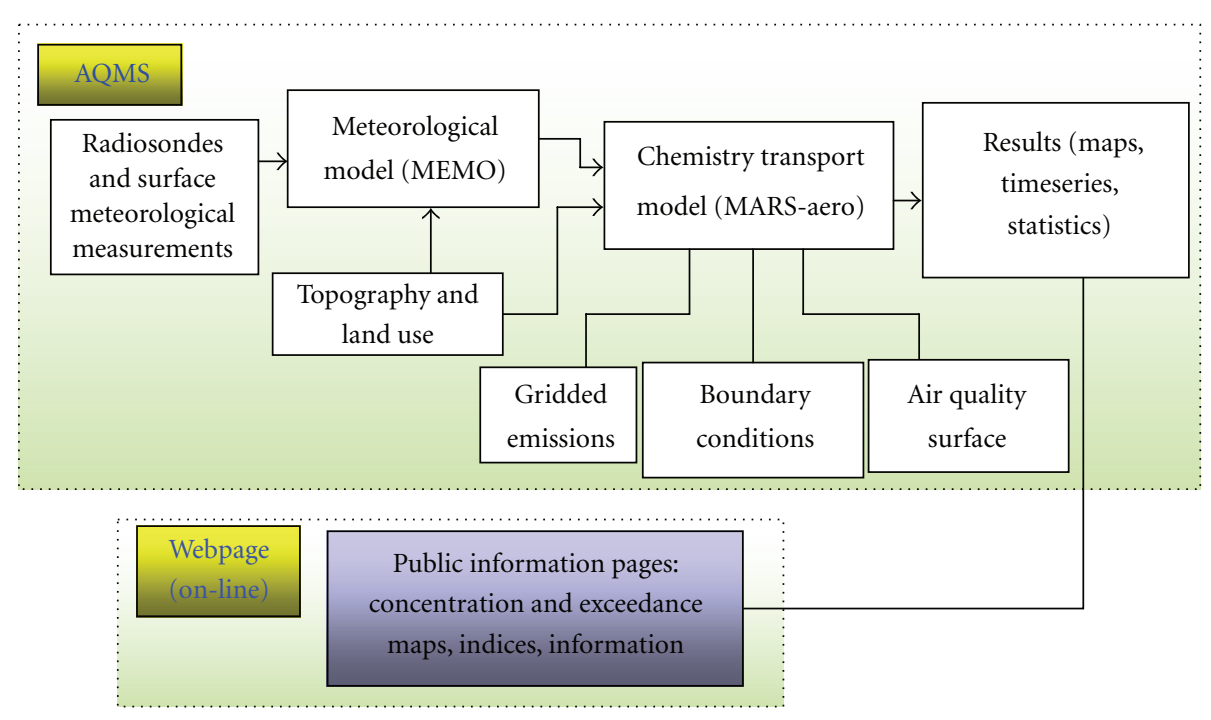

FIGURE 1: The structure of the air quality management system.

The part of the AQMS dealing with the calculation of ambient concentrations has a functional structure similar to that followed by most AQMSs operating on an aroundthe-clock basis (see Figure 1). The AQMS comprises of two operation modes, nowcasting and forecasting, which are implemented based on an automated scheme that performs nested grid meteorological and photochemical model simulations. The mesoscale meteorological model MEMO and the chemistry-transport model MARS-aero are used for this purpose, both parts of the EZM (European Zooming Model) system [4]. MEMO [5] is a three-dimensional, nonhydrostatic, prognostic mesoscale model which simulates mesoscale air motion and inert pollutant dispersion at the local-to-regional scale, over complex terrain, allowing multiple nesting. MARS-aero [6] is an Eulerian chemistrytransport model for reactive species operating at similar scales. The modular structure of MARS-aero allows any of four chemical reaction mechanisms for the gaseous phase to be used, while the calculation of secondary aerosols, organic and inorganic, can be enabled at will [7, 8]. Meteorological data such as wind speed, temperature, TKE, surface roughness, Monin-Obukhov length, and friction velocity are required input for the dispersion calculations and are provided by MEMO. Both MEMO and MARS-aero are used in a nested configuration (see Table 1 ).

For the initialisation of MEMO, a number of vertical profiles of the key meteorological variables originating from the Global Forecast System (GFS) are used [9]. Such profiles are also assimilated into the model calculations on a 3 -hour basis. The downloader module of the automated system undertakes the downloading of the GFS data, processes them, and stores them in a data pool which is kept updated at all times. The scheduler selects only the most recent dataset for input to the MEMO model. Each of these processes keeps a separate event $\log$ and diagnostic files accessible to the operator of the system.

The MARS-aero model runs back-to-back with the MEMO model, featuring real time integration of ambient pollutant concentration data that are provided both from valid measurement data, as well as from larger scale models results and are used both as initial and lateral conditions in the model calculations as well as for data assimilation purposes. An upgraded methodology has been developed and incorporated in the system's core for providing increased flexibility in the coupling of the nested domains. Additionally, a dynamic dust concentration component is included in the $\mathrm{PM}_{10}$ and $\mathrm{PM}_{2.5}$ boundary conditions that are fed in the model core, so as to improve the accuracy of calculated PM concentrations during Saharan dust episodes. These upgrades significantly enhance the operational prognostic skills of the AQMS in the cases of elevated concentration levels that are associated with transboundary transport of air pollutants.

In nowcasting mode the system computes, on an hourly basis, the pollutant concentration fields in Cyprus and, at higher resolution, in the five largest cities. Model results are automatically processed and a range of maps, timeseries graphs, and statistical indices are produced for five major pollutants, namely, $\mathrm{PM}_{10}, \mathrm{PM}_{2.5}, \mathrm{NO}_{2}, \mathrm{O}_{3}$, and benzene. These results become available to the public via DLI's web 


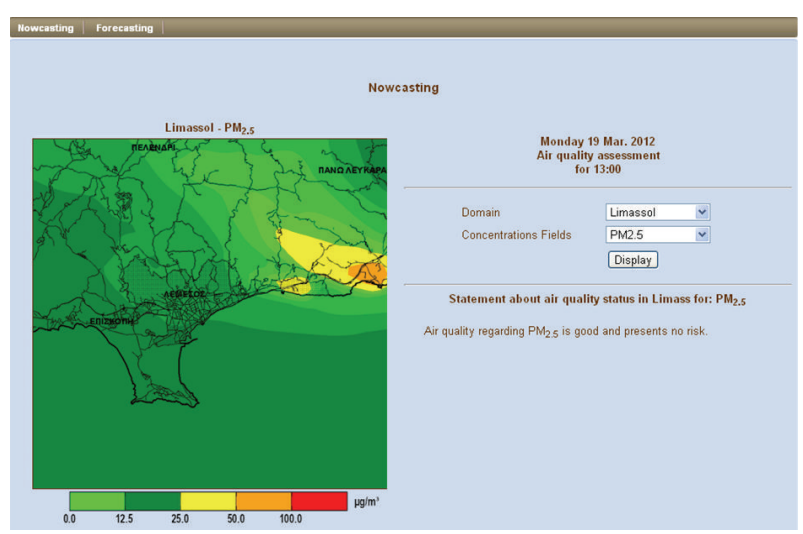

(a)

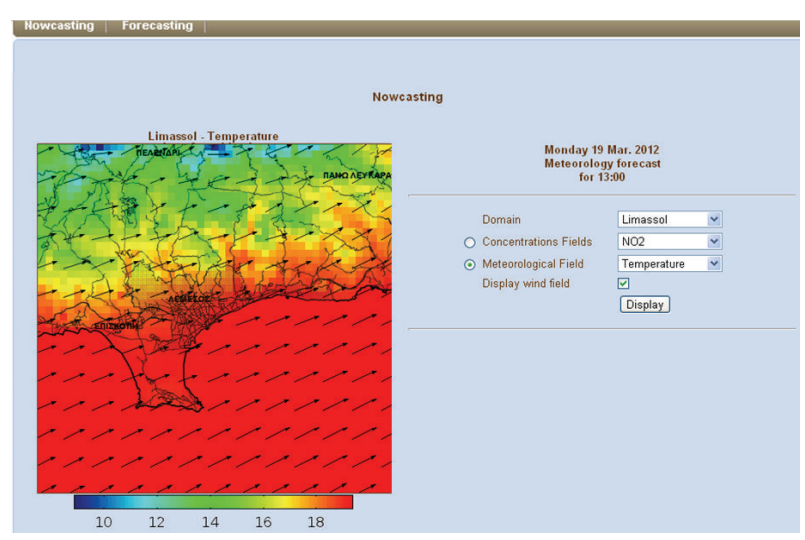

(b)

FIGURE 2: Snapshots of nowcasting for pollutant concentrations (a) and meteorological parameters (b).

page and are also accessible in even greater detail to the staff of the department. In forecasting mode 24-hour photochemical model simulations are driven by corresponding prognostic meteorological simulations of GFS, in order to produce daily air quality forecast maps and graphs for the domains of interest and the prescribed pollutants. Daily forecasts become available to the department and the public through a set of web pages accessible through a similar interface.

The system's user interface is realised as a web-based application which is accessible from any computer having internet access. Through this interface, the authorized DLI users are provided with numerous possibilities for reviewing both the process and the results of the calculations as well as for configuring the information that becomes available in the public web page. The informational public pages represent a very important aspect of the system's structure as, in addition to the concentration levels, the public is also informed on the expected health impacts of the forecasted air quality situation, thus allowing them to manage their activities accordingly.

In order to evaluate the system's performance, suitable statistical indicators are calculated at the end of each day regarding the sites where DLI's air quality measurements take place. An automated procedure operating on an aroundthe-clock basis undertakes the downloading of the available observation data from DLI's server, processes them, and keeps them in a data base, where historical monitoring data are stored. In addition, model results for the measurement locations of DLI's air quality monitoring network are also kept in appropriate data pool. At the end of each day, a wide range of statistical indices are calculated regarding the stations and pollutants of interest and numerous charts are produced, which demonstrate the system's performance in both nowcasting and forecasting mode. In order to have a better overview of the system's efficiency, validation charts are also produced. These charts present comparisons between the calculated and the observed timeseries concerning air pollutant concentration, wind speed, and wind direction.

The AQMS can also be operated by DLI to support airquality-related assessment and decision making, by allowing interactive configuration of custom emission scenarios and corresponding model runs. This operational module provides the capability to study emission scenarios and assess their effect on air quality in the five major urban areas of Cyprus or over user-defined domains. The meteorology used for assessment calculations is based on a number of representative meteorological situations which are analysed and duly weighted according to the frequency of their occurrence during a full calendar year.

\section{Results}

Through the system's interface the public and the authorized DLI users can view the model results, both for nowcasting and forecasting. In the nowcasting section, hourly meteorological and air quality maps are available to any computer with an internet connection through interactive web pages (see Figures 2 and 3). The public is also informed on the expected health impacts of the forecasted air quality situation by messages that are automatically produced and constitute a statement about the expected exposure to air pollution levels on an hourly basis.

Figure 3 demonstrates the gradual dust transport over the Cyprus domain during a typical Saharan dust episode. The system performs reasonably well in predicting the occurrence of Saharan dust episodes. Besides, the model results presented in Figure 3 indicate the high ability of the system in producing the spatial distribution of PM during these episodes.

In the forecasting section of the web interface, a wide range of maps, timeseries graphs, and statistical indices are made accessible to the public, providing information both on forecast pollutant concentrations as well as on meteorological parameters, such as temperature, relative humidity, and wind speed (see Figure 4).

Furthermore, through this interface, the authorized DLI users are provided with geospatial tools for setting up emission scenarios, as well as reviewing the results of the corresponding model runs (see Figure 5). In the scenarios results 


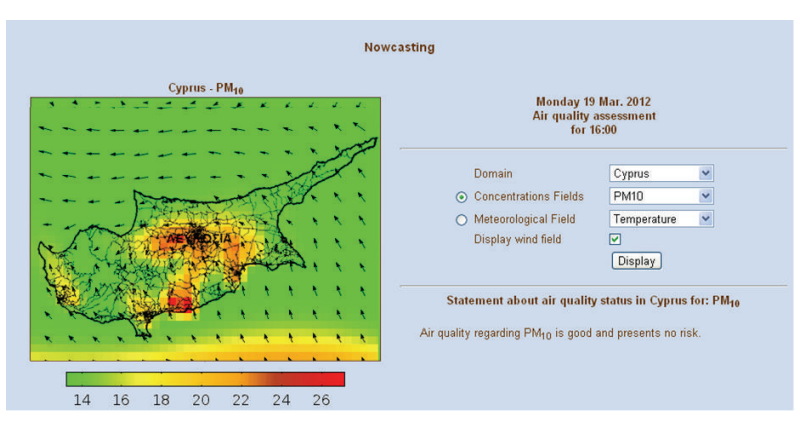

(a)

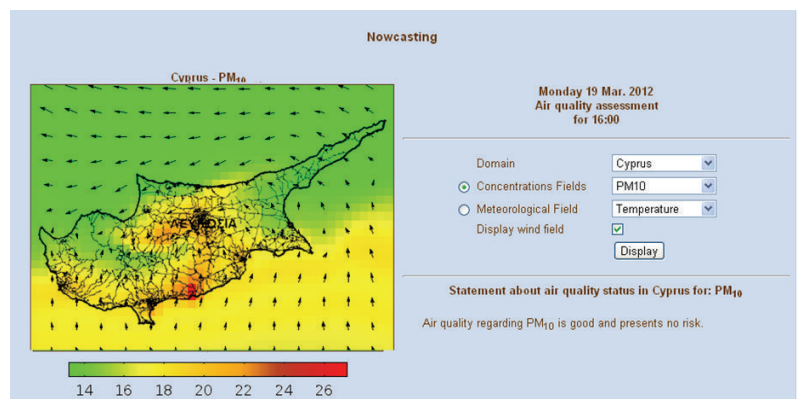

(c)

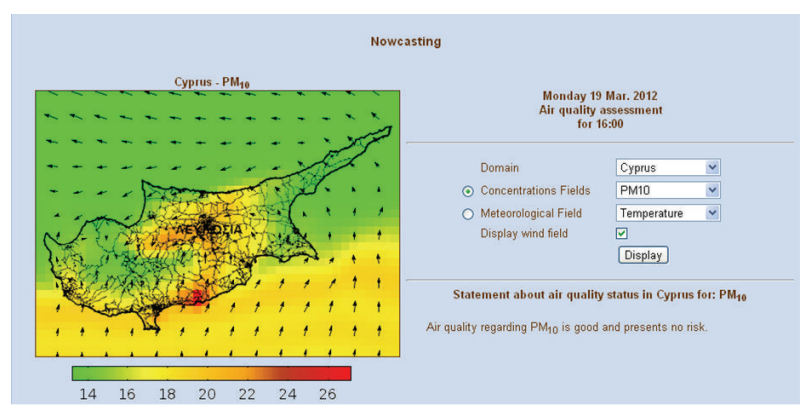

(b)

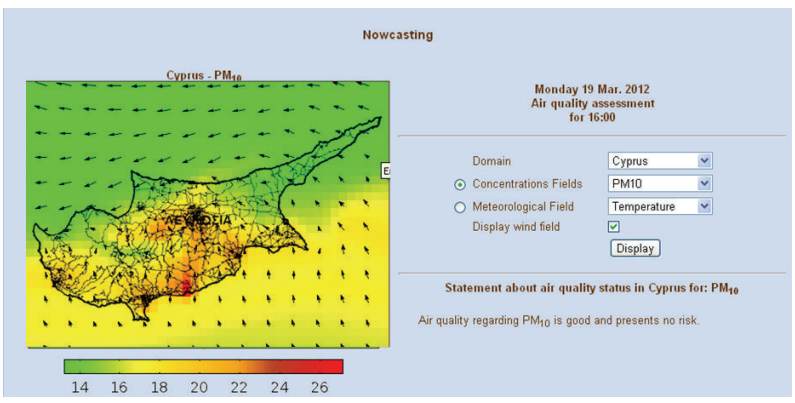

(d)

FIgURE 3: Snapshots of nowcasting results for $\mathrm{PM}_{10}$ during a Saharan dust episode.

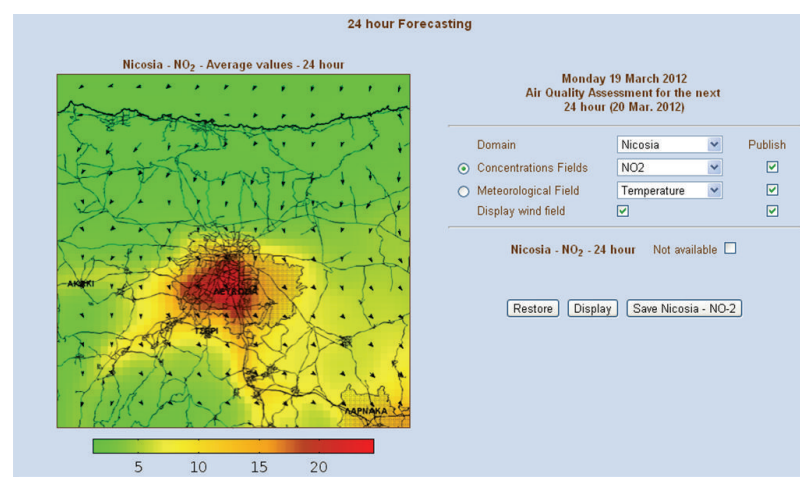

(a)

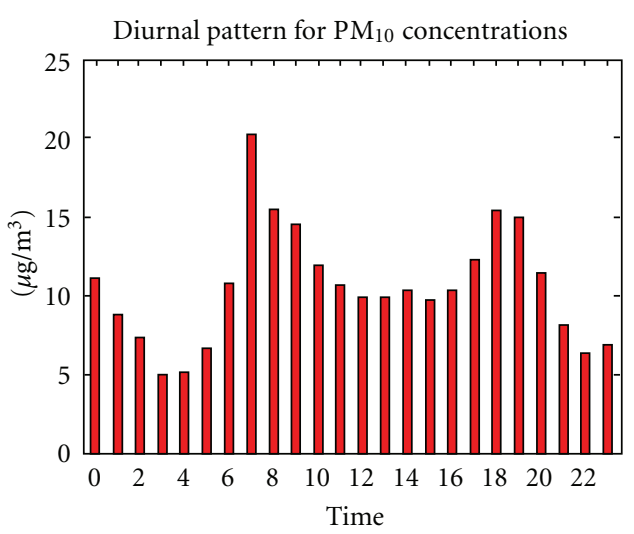

(c)

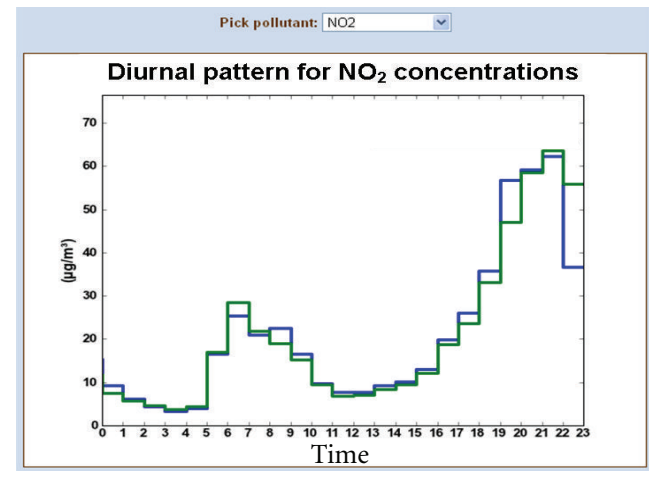

— Nicosia residential

— Nicosia traffic

(b)

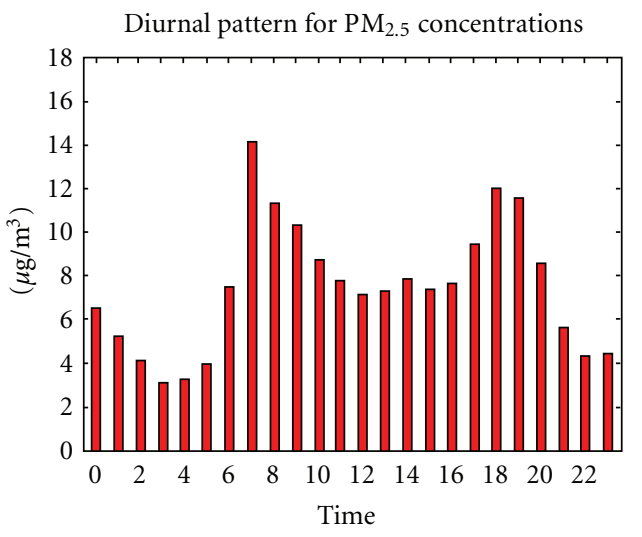

(d)

FIGURE 4: Snapshots of forecasting results for pollutant concentrations. 


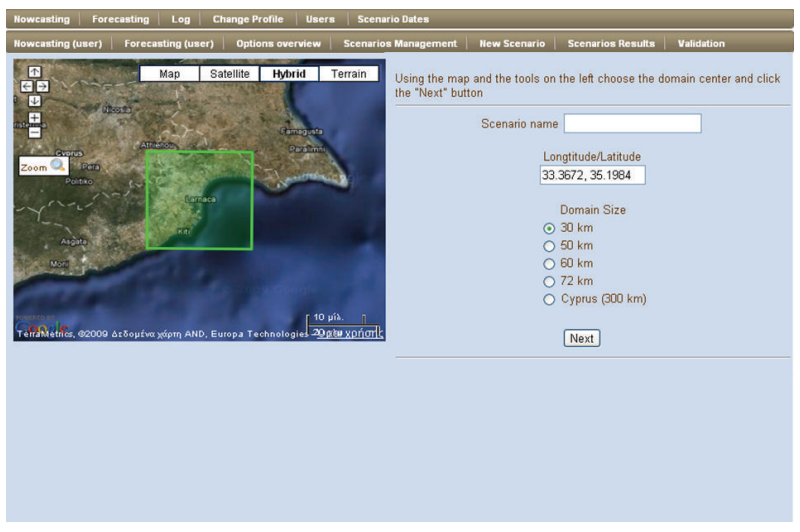

(a)

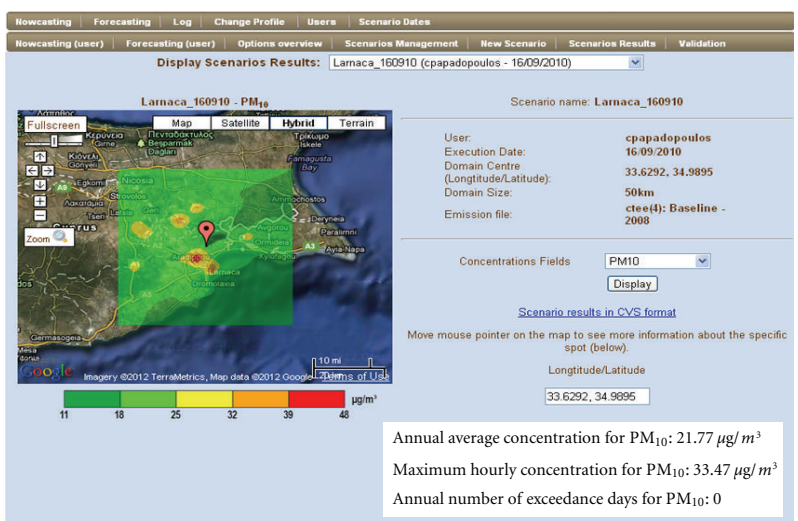

(b)

Figure 5: Emission scenario set up (a) and scenarios results (b).

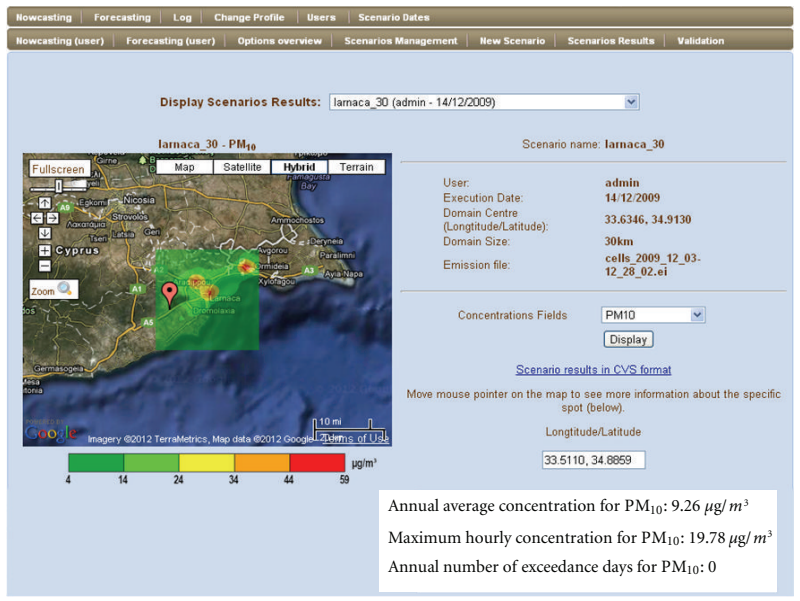

(a)

Concentration diurnal patterns $\left(\mu \mathrm{g} / \mathrm{m}^{3}\right)$
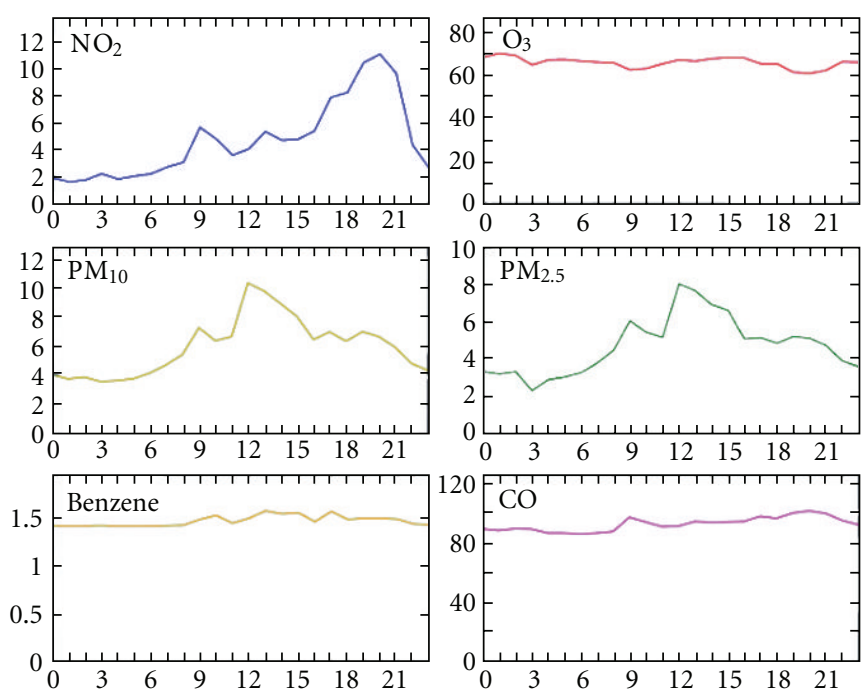

(c)

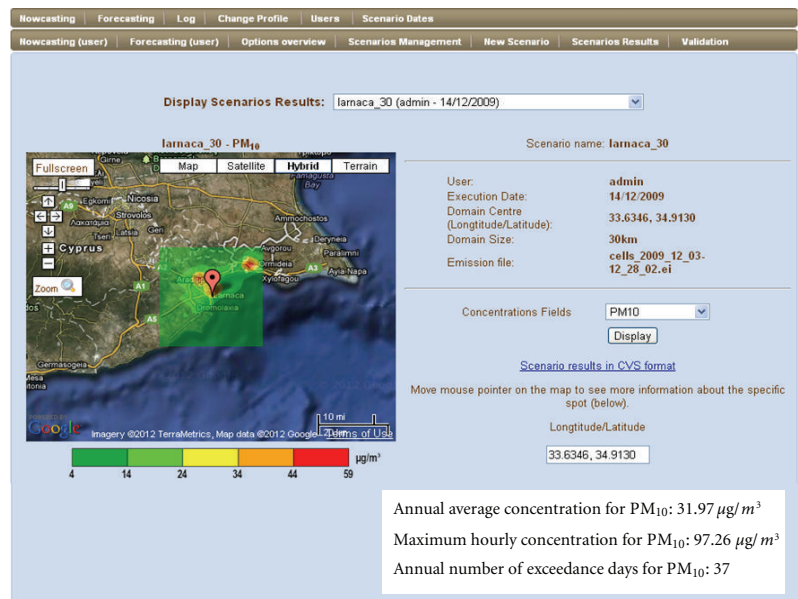

(b)

Concentration diurnal patterns $\left(\mu \mathrm{g} / \mathrm{m}^{3}\right)$
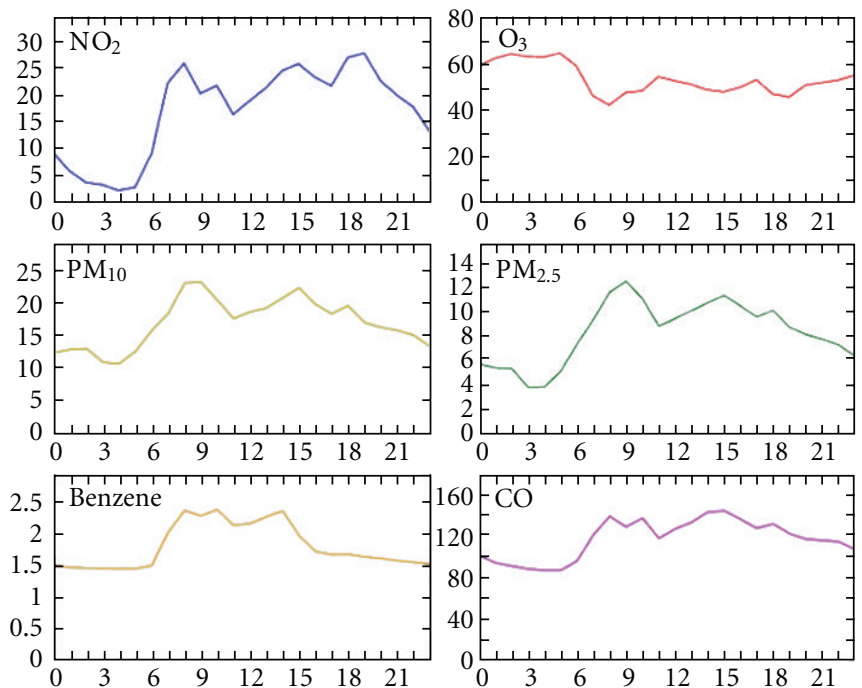

(d)

FIGURE 6: Statistical indices and graphs produced for two different locations inside the computational domain of a particular emission scenario. 
Station $=$ NICO_resi, Date $=04 / 03 / 2010$

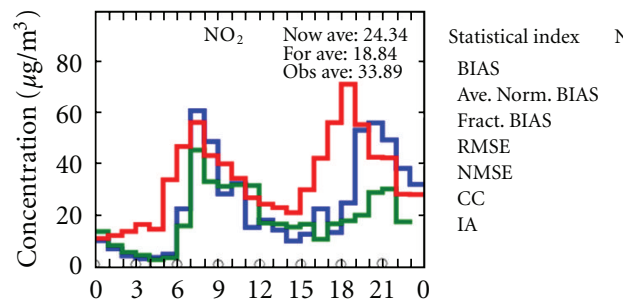

(a)

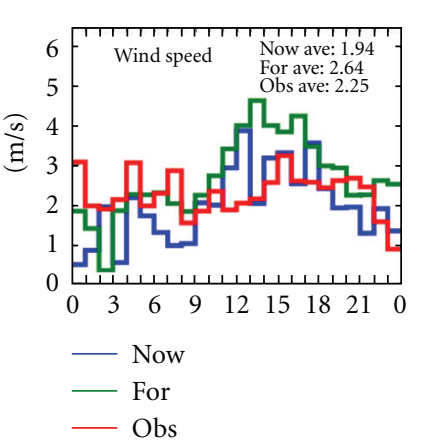

(c)
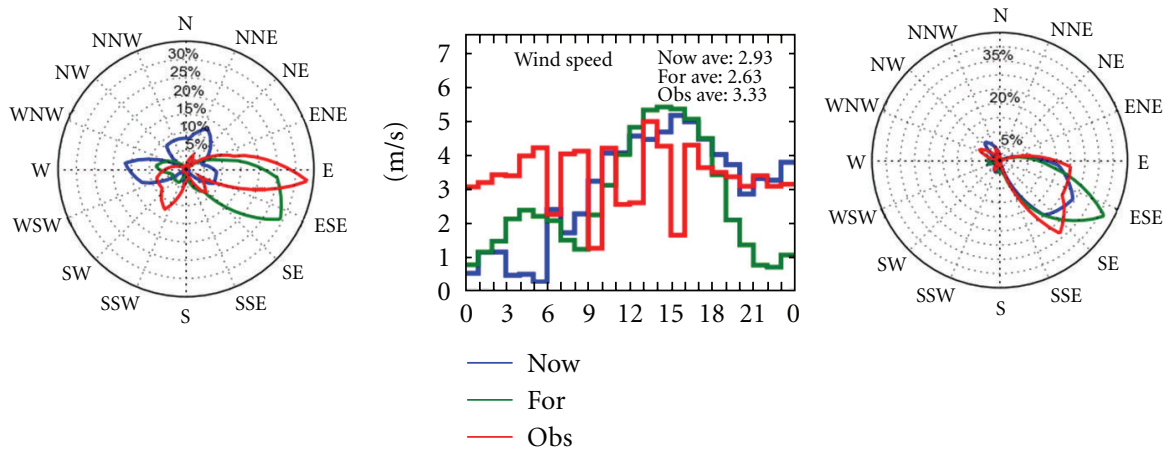

(d)

Figure 7: Air quality and meteorological validation graphs as regards the residential station of Nicosia for the 4th and 10 th of March 2010 concerning $\mathrm{NO}_{2}$ and $\mathrm{O}_{3}$, respectively.

Pollutant $=\mathrm{NO}_{2}$, Date $=11 / 03 / 2010$

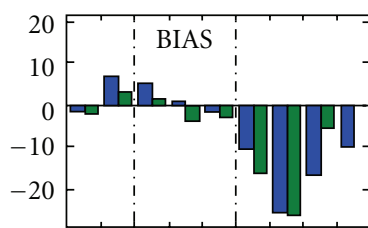

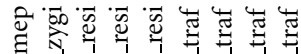

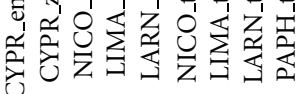

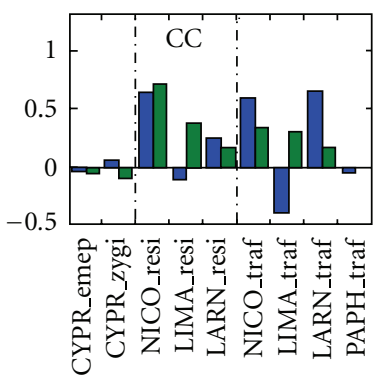

$\square$ Now

$\square$ For

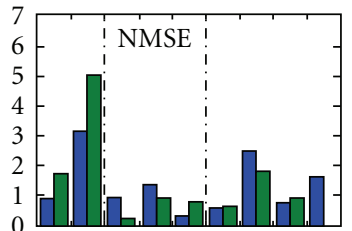

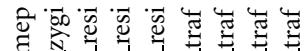

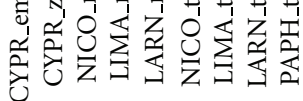

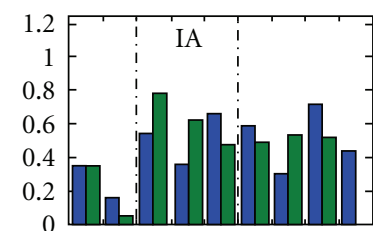

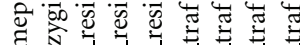

品

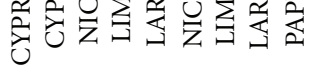

$\square$ Now

$\square$ For

Pollutant $=\mathrm{O}_{3}$, Date $=11 / 03 / 2010$

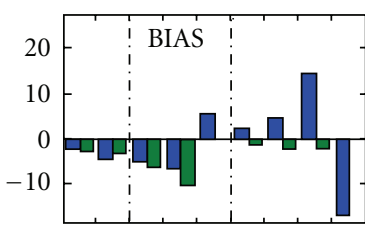

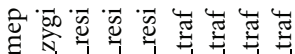

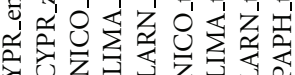

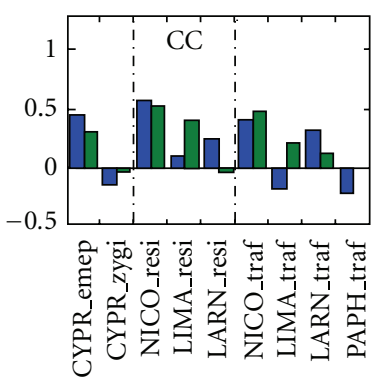

$\square$ Now
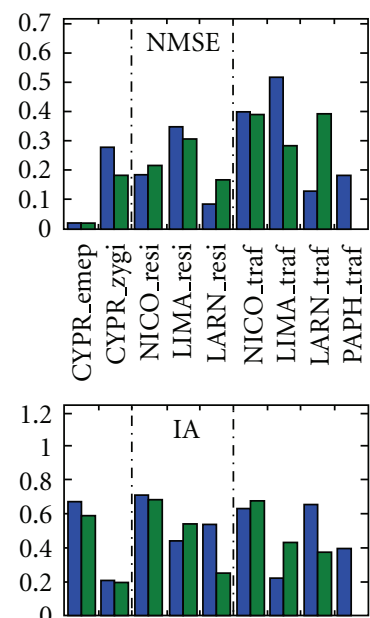

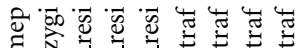

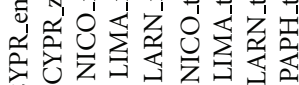

$\square$ Now

(a)

(b)

Figure 8: Statistical indices calculated for the 11th of March 2010 as regards $\mathrm{NO}_{2}$ (a) and $\mathrm{O}_{3}$ (b). 


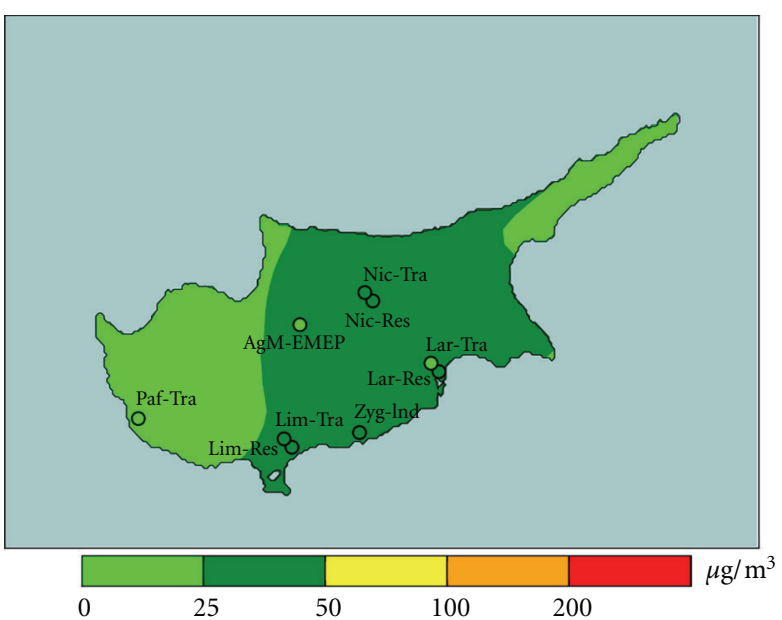

(a)

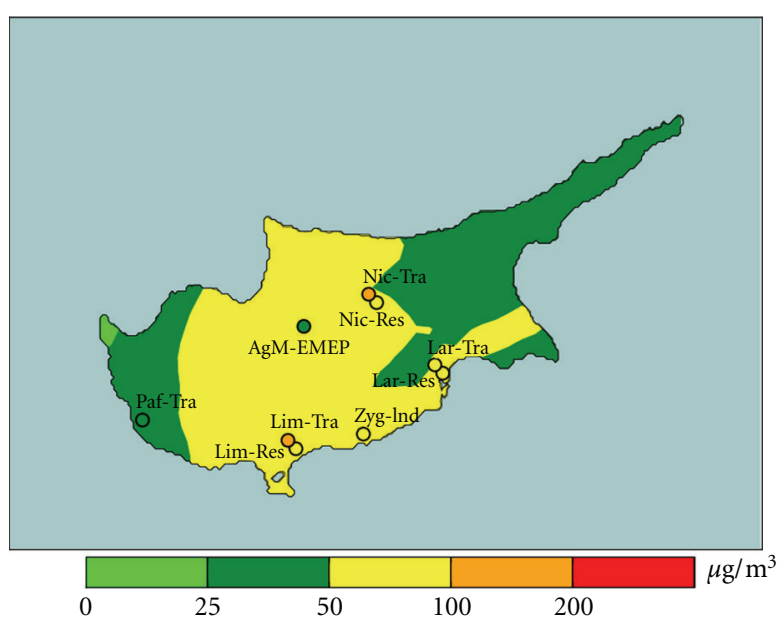

(b)

FIgURE 9: Validation maps as regards $\mathrm{PM}_{10}$ for a typical winter day (a) and a day in which a slight Saharan dust episode occurs (b).

section, the DLI user can not only access pollutant concentration maps produced by the automatic process of the respective model runs but also to manually produce statistical indices and timeseries graphs for any location inside the calculation domain, using a suitable interactive feature (see Figure 6).

In Figure 7 air quality and meteorological validation graphs as they are operationally produced by the system are presented. Each graph shows comparisons between model simulations and the respective observation data regarding air pollutant concentrations, as well as wind speed and direction. Additional information about the model accuracy is also provided in the form of statistical indices, namely, "BIAS", "Average Normalised BIAS" (ANB), "Fractional Bias" (FB), "Root Mean Square Error" (RMSE), "Normalised Mean Square Error" (NMSE), "Correlation Coefficient", and "Index of Agreement". In this field of the graphs, green colour indicates which mode between nowcasting and forecasting operates better according to each statistical index.

As depicted from Figure 7, the system's performance as regards the suburban areas is good in the case of $\mathrm{O}_{3}$, where concentration levels are determined by the transboundary transport which enters the model as initial and lateral boundary conditions from the results of larger scale models. On the other hand, the supplementary use of air quality measurements in the formation of the boundary conditions leads to increased model efficiency in the cases of air pollutants which are related to human activities, such as $\mathrm{NO}_{2}$. This fact occurs because most of DLI's measurement stations are located close to areas which contain a wide range of human activities, including transport and industry, and as a result, the obtained concentration values are affected by the aforementioned activities. Thus, the exploitation of observation data as boundary conditions of the model simulations improves the system's computational performance in assessing air pollutant levels mostly influenced by human activities.

Figure 8 presents a subset of the calculated statistical indicators, namely, "BIAS," "Normalised Mean Square
Error," "Correlation Coefficient," and "Index of Agreement," for three typical days regarding nitrogen dioxide $\left(\mathrm{NO}_{2}\right)$ and ozone $\left(\mathrm{O}_{3}\right)$. As evidenced from the indicators shown in Figure 8 , the results of the model are in fairly good agreement with the observed concentrations, the only exceptions being the industrial and traffic stations. This is more or less expected for these hotspots that are highly affected by local and street scale activities.

Figure 9 shows validation maps as regards $\mathrm{PM}_{10}$ for a typical winter day and a day in which a slight Saharan dust episode occurs. In these maps the calculated model concentration maps are compared to the concentrations observed at the measurement locations at the same time.

\section{Conclusions}

The AQMS developed and installed in the Department of Labour Inspection of the Republic of Cyprus is an integrated operational state-of-the-art air quality management system for meteorological and photochemical model simulations which offers a range of features for nowcasting, forecasting, and performing scenario calculations for air quality in areas of interest. Results of the calculations can be reviewed in detail by the DLI, while they can also be accessed in a condensed form by the general public via a user friendly web page. In order to evaluate the system's performance, suitable statistical indicators are calculated at the end of each day for the measurement locations of DLI's air quality monitoring network. Besides, validation charts are also produced, presenting comparisons between the calculated and the observed timeseries concerning air pollutant concentration, wind speed, and wind direction. The AQMS can also be operated by authorised DLI users to support air-quality-related assessment and decision making by performing air quality calculations based on custom emission scenarios. The capabilities offered by this AQMS for producing high-quality assessments of the air quality situation are expected to be 
a valuable aid to the authorities of Cyprus towards compliance with the relevant EU standards.

\section{Acknowledgments}

This work was cofinanced by the EU in the framework of the transition facility 2005 for Cyprus. The authors would also like to thank the director of DLI Leandros Nicolaides and the DLI team involved in the project.

\section{References}

[1] COST728, Overview of Tools and Methods for Meteorological and Air Pollution Mesoscale Model Evaluation and User Training, 2008.

[2] http://www.airquality.dli.mlsi.gov.cy/.

[3] S. Kleanthous, G. Tsegas, I. Douros, and N. Moussiopoulos, "An air quality management system for Cyprus," in Proceedings of the 7th International Conference on Air Quality-Science and Application (Air Quality '09), R.-M. Hu, Ed., pp. 405-408, CDROM edition, Istanbul, Turkey, March 2009.

[4] N. Moussiopoulos, "The EUMAC Zooming Model, a tool for local-to-regional air quality studies," Meteorology and Atmospheric Physics, vol. 57, no. 1-4, pp. 115-133, 1995.

[5] N. Moussiopoulos, T. Flassak, P. Sahm, and D. Berlowitz, "Simulations of the wind field in Athens with the nonhydrostatic mesoscale model MEMO," Environmental Software, vol. 8, no. 1, pp. 29-42, 1993.

[6] N. Moussiopoulos, P. Sahm, and C. Kessler, "Numerical simulation of photochemical smog formation in Athens, Greece-a case study," Atmospheric Environment, vol. 29, no. 24, pp. 36193632, 1995.

[7] A. Arvanitis, N. Moussiopoulos, and S. Kephalopoulos, "Development and testing of an aerosol module for regional/urban scales," in Proceedings of the 2nd Conference on Air Pollution Modelling and Simulation (APMS '01), pp. 277-288, Champssur-Marne, April 2001.

[8] B. Schell, I. J. Ackermann, H. Hass, F. S. Binkowski, and A. Ebel, "Modeling the formation of secondary organic aerosol within a comprehensive air quality model system," Journal of Geophysical Research D, vol. 106, no. 22, pp. 28275-28293, 2001.

[9] http://www.emc.ncep.noaa.gov/gmb/moorthi/gam.html. 

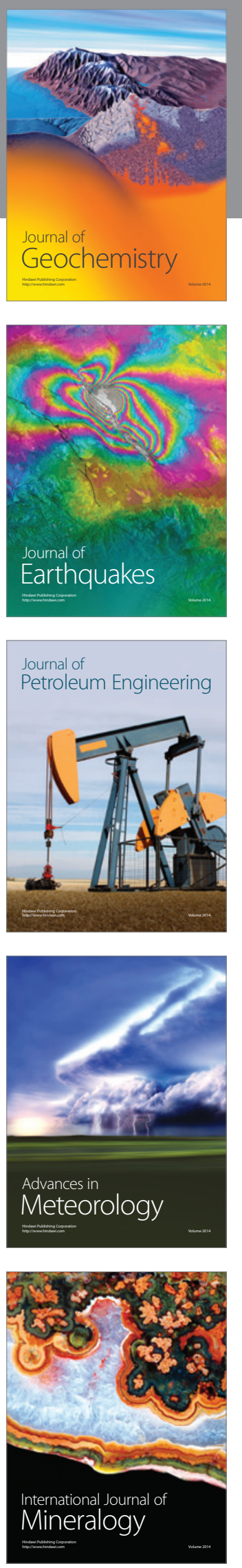
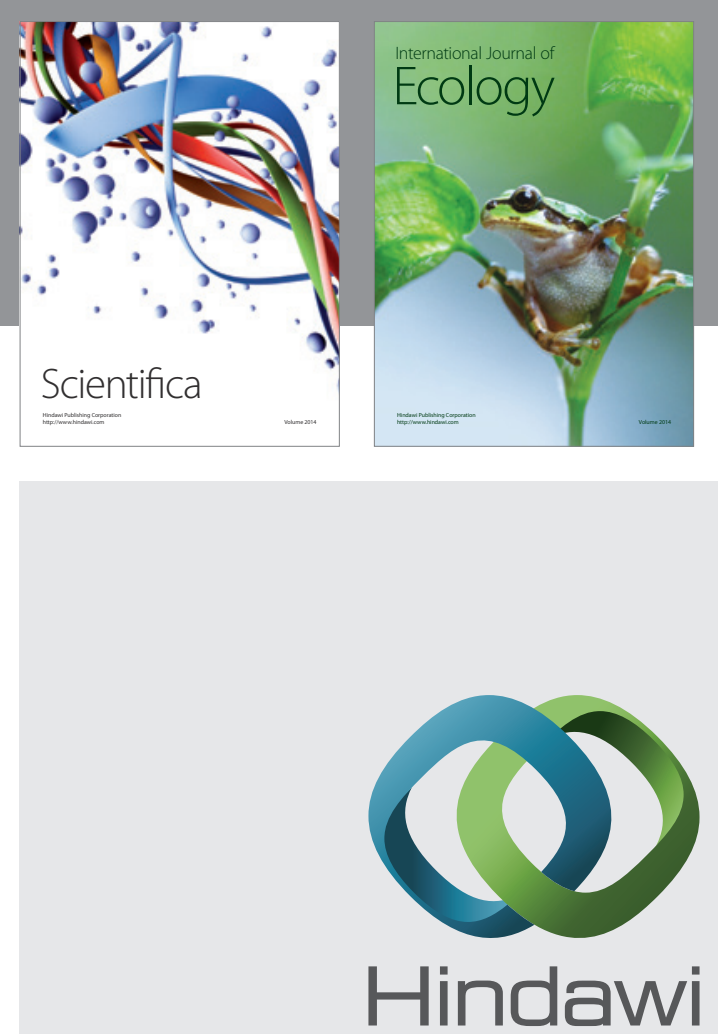

Submit your manuscripts at http://www.hindawi.com
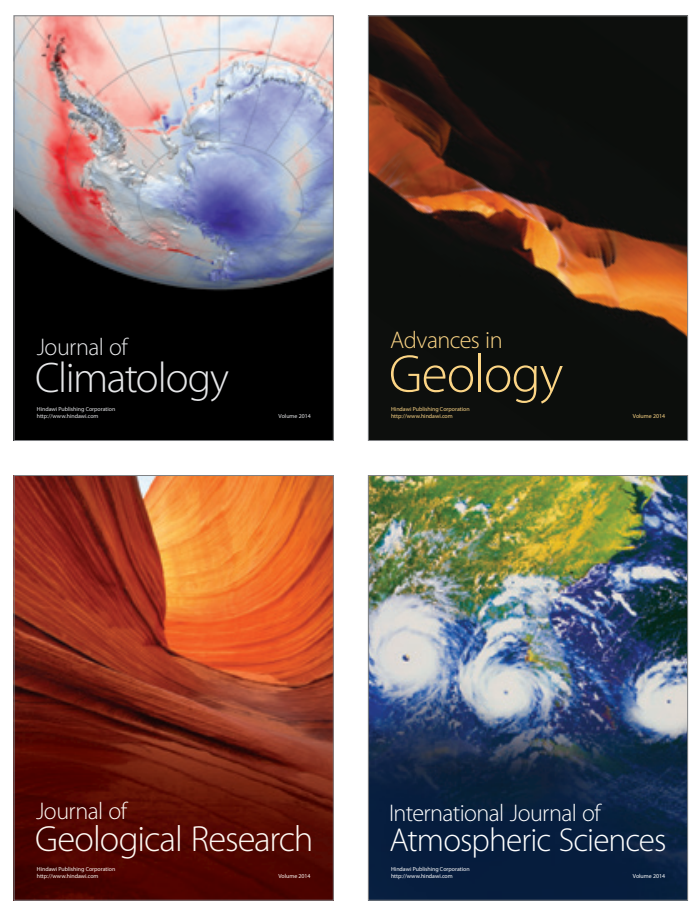
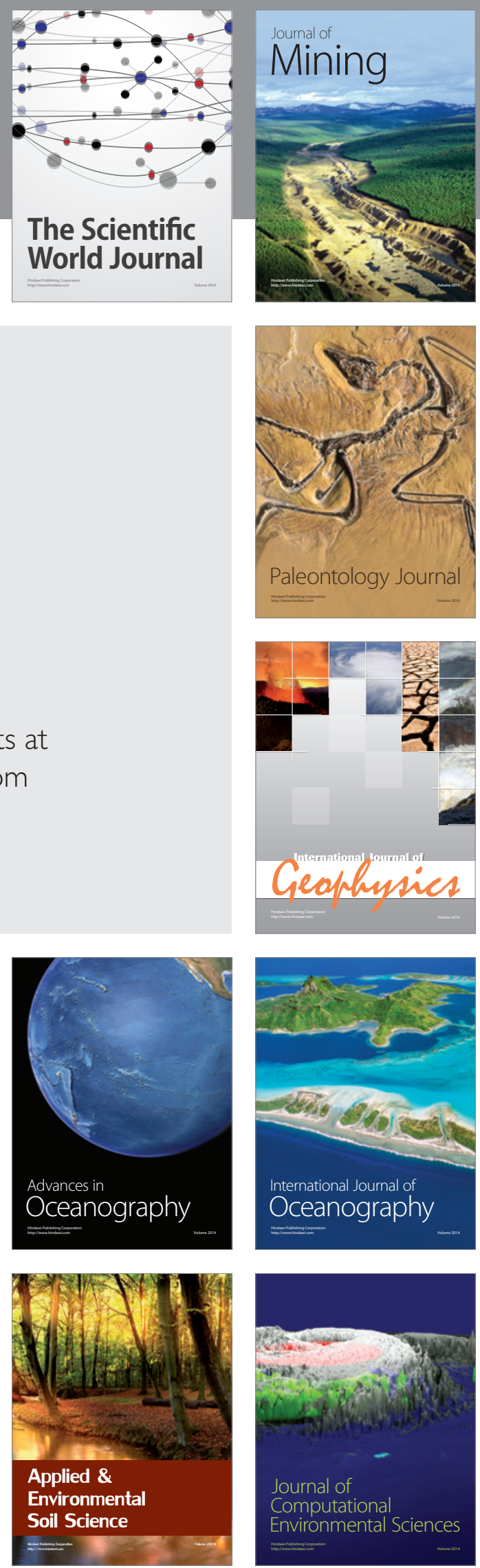